\title{
Selection of a tool to decision making for site selection for high level waste
}

\author{
Jonni Guiller Madeira ${ }^{1 *}$, Antônio Carlos M. Alvim², Vivian B. Martins ${ }^{2}$, and Nilton A. Monteiro ${ }^{2}$ \\ ${ }^{1}$ Celso Suckow Fonseca Federal Center for Technological Education-(CEFET), Areal street, 522 Sq. Mambucaba, Angra dos \\ Reis, Brazil \\ 2 Nuclear engineering program-(PEN/UFRJ/COPPE-RJ), Federal University of Rio de Janeiro, Horácio Macedo avenue 2030, \\ Technology Center Building, University City, 21941-972 Rio de Janeiro, Brazil
}

Received: 25 May 2015 / Accepted: 27 November 2015

Published online: 10 February 2016

\begin{abstract}
The aim of this paper is to create a panel comparing some of the key decision-making support tools used in situations with the characteristics of the problem of selecting suitable areas for constructing a final deep geologic repository. The tools addressed in this work are also well known and with easy implementation. The decision-making process in matters of this kind is, in general, complex due to its multicriteria nature and the conflicting opinions of various stakeholders. Thus, a comprehensive study was performed with the literature in this subject, specifically in documents of the International Atomic Energy Agency (IAEA), regarding the importance of the criteria involved in the decision-making process. Therefore, we highlighted six judgment attributes for selecting a decision support tool, suitable for the problem. For this study, we have selected the following multicriteria tools: AHP, Delphi, Brainstorm, Nominal Group Technique and AHP-Delphi. Finally, the AHP-Delphi method has demonstrated to be more appropriate for managing the inherent multiple attributes to the problem proposed.
\end{abstract}

\section{Introduction}

Nowadays, considering the increasing demand for power, and the environmental issues, it is ever more necessary to adopt (and create) new alternative sources of power, economically viable and with low environmental impact. In this sense, because of environmental, social and political concerns, recently, the nuclear power has drawn the global attention.

The environmental impact is potentially the most relevant topic concerning the suitability of nuclear power [1]. And, since global warming has been the key topic of several discussions over the last years (it is believed that such phenomena is generated by the greenhouse gases [GHG]: water vapor, methane and $\mathrm{CO}_{2}$ ), it increases the environmental advantages of nuclear power plants. Among such advantages, it is possible to mention that a smaller space may be quite satisfactory for its construction, also it is quite free from polluting gases emissions such as $\mathrm{CO}_{2}$ and methane [2]. However, one of the most challenging questions to be answered, regarding nuclear power, is the

\footnotetext{
* e-mail: guiller.nuclear@ufrj.br
}

appropriate location for nuclear power plants construction and location for nuclear wastes.

Since the early 1970's, a rising concern with the final (or temporary) disposal of radioactive wastes has been noticed. This rising attention on nuclear wastes questions has generated an economic and safety assessment that sought to optimize the cost-benefit of these repositories (storage location for disposal of radioactive wastes). Also, several authors have been discussing about this issue [3-14].

Altogether, there is not many countries with final repositories (for radioactive wastes) working. However, some countries, as Finland, e.g., are making a great progress building deep final repositories [14].

Thus, regarding the place selection for safely housing a deep geological repository, we have walked into a decisionmaking issue, since we need to choose, among the likely possibilities, one that meets the several points required for; and also that best fits these points, as deep geological repository for radioactive waste, emphasizing the spent fuel.

The process of decision-making involves various specialties from different fields, considering it is a multicriteria problem. In this case, we need a decision support tool that can arrange the specialists' opinions within the context of place selection. 


\section{Geological disposal of nuclear wastes}

During the nuclear power plant operating life, it is necessary to replace part of the reactor core fuel periodically. This spent nuclear fuel is called (if it has no other use) nuclear waste, which, besides emitting radiation and heat, contains high amounts of radioactive nuclide. A delicate point in handling such nuclear waste is the emission of radiation for a very long time, what shall reach thousands, or even millions of years.

There are thousands of tons of spent fuel waiting for a solution for its final disposal, which puts this question among the main concerns on the construction of a nuclear power plant [15].

A deep geological repository is the most used solution in countries where high level nuclear wastes management is adopted already. Also, in the EURADWASTE and IAEA Conference, it was largely discussed that deep geological repositories are hitherto the safest and workable measure for nuclear waste.

A deep geological repository is a nuclear waste repository excavated deep within a stable geologic environment (typically below $350 \mathrm{~m}$ or $500 \mathrm{~m}$ ) in order to avoid for a long time the biosphere contamination with the radioactive nuclide [16]. Such isolation, in this type of disposal, ensures safety until the nuclear fission products decay and reach acceptable radiation levels. It entails a combination of waste form, waste package, engineered seals and geology that is suited to provide a high level of longterm isolation and containment without future maintenance. This feature must inhibit the motion of radioactive nuclide into the middle of the external repository, ensuring future safety for humans and environment [17]. Ratifying, all these details are essential to ensure the future safety of deep geological repositories.

\section{Decision support tools}

One of the most important tasks faced by decision makers is selecting a site that meets the various criteria considered for constructing the final deep geological repository for nuclear wastes.

This site selection requires a multicriteria analysis with an analytical solution. Since it deals directly with conflicting criteria, e.g., demography, there would be advantages and disadvantages. For example, if a deep geological repository for high level waste is constructed in a high population density area, there would be advantages in transportation, such as easy roads access - making it easier to get workforce. However, this same location may directly affects the population because it could increase the risk for people.

Multicriteria analysis is done considering internationally accepted factors as essential for the suitability of a place for a deep geologic repository construction such as lithology, relief, transportation, among others.

Generally, there are many technical requirements to be properly fulfilled in place selection. Thus, the tools shown below orient this dynamics of the selection process.

\subsection{AHP}

Multiple-Criteria Decision Making (MCDM) occurs in cases where it is necessary to analyze decision situations that embody both quantitative and qualitative criteria, conflicting or not. The AHP is one of the most known and used methods of MCDM [18].

Analytic Hierarchy Process (AHP) is a tool that drives decision makers to meet the best solution that suits their goal and their understanding of the problem, leading them to a structured reflection on solving it in a constant process of acquisition of knowledge. The AHP seeks to reproduce what seems to be a natural method of human mind in perceptions and judgements [19]. This technique was developed by Saaty [20] (1980) and it is based on pairwise comparisons of criteria, in order to create a relationship matrix (proportion).

This decision support tool is characterized by its simplicity and efficiency, what makes its use possible in several fields, including: Strategic Planning [21], Marketing [22] and Consensus-based assessment [23], Funding and financing Choice for Air Transport [24] (1998), Quality and Productivity Programs [25] and Project Analysis [26].

The AHP may incorporate both qualitative and quantitative factors in the decision-making process [27], so it is possible to deal with the inherent subjectivity of this selection process.

Although it is a very effective tool [28], it highlights some disadvantages of AHP technique:

- once the scale is subjective, it is liable to human error;

- it is vulnerable to human psychology;

- the number of comparative tables may be too large if many attributes of comparison are used, creating, so, a tendency to exclude them;

- there is a limit on the hierarchy levels (number) that can be used;

- it is necessary a series of pairwise comparisons of the elements for very large problems;

- ambiguous and inconsistent judgments by the decision maker may be critical.

\subsection{Delphi}

Its use is recommended, either, when it has no measurable data about a problem, as when there is. Also, its application is best suited when there is no historical data regarding the problem being investigated or, in other words, when quantitative data relating to the issue under examination is insufficient $[29,30]$.

This technique shows a good performance on medium and long-term forecasts [31], also its use has other benefits, according to Preble: zero contamination of results; efficient use of the experts' intuition; results easily understood by lay people; unambiguous communication between participants, and procedure documentation [32].

Delphi is largely used in tasks of technological or marketing forecasting, in fields such as Project evaluation, Investment analysis and Financial planning [33]. 
Although Delphi is a good and very used research tool, there is no consensus about its methodological validity, so, raising several criticisms about it. Wheelwright and Makridakis describe some of these criticisms, and they are related to insufficient reliability: possibility to calculate different results by using different specialists; unable to predict the unexpected; difficulty of assessing the specialization level (expertise), etc. [34].

Sackman, the greatest critic of Delphi, condemns even its anonymity. Despite the advantages of anonymity among experts, the process is inevitably doomed to transparency loss due to the tool inherent secrecy [35].

Some factors leading Delphi to failure, according to Linstone and Turoff are: biased point of view (of the research monitor), the use of poor techniques summary of the results, to ignore and do not explore points of disagreement, so resulting in an artificial consensus, etc. [36].

\subsection{Brainstorming}

Brainstorming is a technique for group dynamics, its use encourages participants to release their ideas; it is marked by the lack of restrictions or inhibitions.

Due to the large flow of ideas, participants can create new possibilities and resume them, especially those that had not been taken into consideration. Indeed, this technique works as an ideas' conductor (a guide for), allowing the group to achieve improvements in a relatively small period.

Some benefits provided by the decision support tool for decision making in group:

- it quickly provides a large volume of ideas;

- it stimulates creativity and innovation;

- it encourages the engagement of the participants;

- it generates opening to the use of other tools.

Brainstorming is used in several fields because it is easy to be implemented. Also, it is used in the advertising industry, for creating ideas, in software optimization, in creation of electronic medical records, and for information systems, in situations with multicriteria and in any other field that needs to develop or create ideas for a particular purpose.

Collaborative tools such as brainstorming, can present problems. Some of them may be found in collaborative environments [37]:

- difficulty to finding a suitable common time and location to all group members;

- difficulty to ensure active and equal participation to all group members;

- difficult to objectively conduct the meeting, not wasting people's time;

- difficulty to converge to a satisfactory solution.

\subsection{Nominal Group Technique}

The Nominal Group Technique (NGT) is an alternative way to conduct a brainstorming, in a structured way. It is based on the concept that it is possible to add procedures to brainstorming, so optimizing some results [38].

This technique was created by Andre Delbecq and Andrew VandeVen in 1971. The term "nominal" suggests that it is a process of group interaction, but does not allow verbal communication between participants.

The NGT is adopted in situations where it is necessary to formalize and control the brainstorming sessions, the socalled structured brainstorming. This can occur essentially in two situations: when it is necessary to document, in details, the participants' ideas; or to avoid that excessive extroverts participants inhibit others. This method is widely used in various areas of knowledge such as engineering and nursing [39-41].

As well as brainstorming, this technique is used in conjunction with other tools. There are numerous applications for this technique, among which it is possible to highlight: the definition of priorities for action in groups, the problems' roots identification, and/or group work on alternative solutions.

The disadvantages are related to limitation of the technique, since it handles only a problem a time, it allows the participation of a maximum of nine people per group (it is necessary to create several groups if there is a large number of participants), also, it is not suitable for simple problems that can be solved in less structured groups.

\subsection{AHP-Delphi}

The Delphi-AHP is applicable to a wide range of complex, and multicriteria decisions that require judgments about qualitative characteristics of some evaluators group, that in the case of our question, are the experts.

According to Jessup and Tansik, the integration of AHP in a Delphi table increases the functionality of AHP, by using it in an iterative sequence of individual questioning and anonymous commentaries [42]. This combined tool promotes the participants' judgment on issues that are not necessarily their specialty due to multicriteria characteristic of the problem.

Wilkinson has noted that the assessment of the feasibility of alternative projects, for information system, requires that evaluators carry out a series of subjective judgments, and concludes that a structured medium such as Delphi-AHP is necessary to incorporate intangibles factors [43]. Kaplan and Atkinson also recognize the necessity of using AHP-Delphi to integrate qualitative criteria in Management accounting systems to support efforts in order to improve quality and productivity, thus helping to justify investments in new production technologies $[44,45]$.

\section{Scoping the problem}

The method will be applied for selecting a decision support tool able to point a site, for a final deep geological repository. This tool must possess specific features that meet the needs of this multicriteria problem, providing a solid and consistent result. 
According to IAEA albeit - for selecting a place for a deep geological repository - each country has its specificities, political, cultural, and others, the rules for decision making will, quite often, need of criteria definition and evaluation methods [17]. Thus, it is necessary to clearly point out the criteria applied. This meticulous analysis aims to maximize safety and ensure transparency for stakeholders.

The following criteria were based on an extensive literature review. The International Atomic Energy Agency have issued several guidelines addressing the topic and advising on possible features of the decision problem relating to a final deep geological repository [46-48].

Decision support tools will be compared according to the following criteria:

- transparency and reliability: it should be considered a transparent and traceable method, that take into account the various groups (stakeholders) allowing them to best follow and understand every decision made during the process [14];

- subjectivity: a high level subjectivity nurtures disagreement among experts (once there are experts from different areas of knowledge), which may create a dispute in comparing the judgment elements; also it may complicate the obtaining and the analysis of final result. Thus, a tool with low level of subjectivity in a multicriteria problem is important because it enables an ease of communication and agreement among experts; - updating and adapting: according to documents published by the IAEA during the 1980s, the process of final deep repository siting is performed in "adaptive" steps, lasting several years, which will evolve as long as decision makers have considered every participants' judgment. Thus, the implemented tool must be able to update its results, then allowing the review and selection, if necessary, of new candidate sites - if necessary too - in order to reduce the inconsistency between different views of groups, and deal with new information emerged along the process;

- multicriteria analysis: this technique has problems related to many variables. The different criteria used in the problem must be contextualized in the same interface to enable a final judgment unique, and theoretically consistent. In general, multicriteria decision problems involve a set of alternatives that are evaluated based on conflicting and incommensurate criteria $[49,50]$. Thus, we need a decision support tool that can analyze a multicriteria problem in a fair and balanced way, as the relative importance of each criterion.

The question of final deep repository siting, as well as most of multicriteria problems, involves six components [51]:

- a goal, or set of goals, the decision maker seeks to achieve,

- a decision maker, or the whole group involved in the decision-making process, have their own preferences concerned to the assessment criteria,

- a set of evaluation criteria (objectives and/or physical attributes),

- a set of decision alternatives,
- a set of uncontrollable variables (independent) or "states of nature" (decision environment),

- a set of outcomes or consequences associated with each pair of alternatives and attributes;

- ease of deployment: any decision support tool has some difficulty on being implemented, whether technical or not. This difficulty in decision making is based on typical features of the problem, such as a large number of experts, many science fields involved, and the attributes subjectivity. Thus, it is noteworthy that to decrease the process costs is necessary a tool that can be easily used. The ease of deployment is also tied to updating and adapting criteria, if new assessments were required, the new results may be obtained faster, and sometimes, with no many additional costs;

- application time: due to a large number of experts required for the problem solution, a too long process may result in loss of judgment quality motivated by fatigue. Thus, the ideal decision support tool is a non (time) extensive.

\section{Comparative table with the attributes}

Table 2 shows a comparison between different attributes of the decision support tools, based on a point scale, as described in Table 1.

\section{Conclusion}

In an individual decision making, people only have to agree with themselves; but in group, problems of consensus will certainly occur. Therefore, there must be a tool able to assist the group in a decision-making process.

The Delphi method has a big advantage regarding information about the deep geological repository siting, since it is very effective when the goal is to improve the understanding of the problem (once the problem is multicriteria and involves experts from different fields); this tool has advantages, over brainstorming and NGT. Brainstorming, as well as the Nominal Group Technique, due to the large flow of ideas, do not have an informative profile, so, being best suited for early steps of the project, when there is no one idea yet, and they are clearly required.

As the presented problem requires several experts with different academic backgrounds and different personalities, it is necessary to avoid confrontation between them. The anonymity during this process can eliminate the influence

Table 1. Service level of attributes by decision support tools.
Very poor
Poor
Average
Good
Excellent

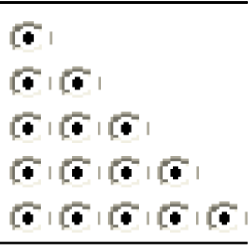


Table 2. Comparative table of attributes to decision support tools, based on quantitative criteria.

\begin{tabular}{|c|c|c|c|c|c|}
\hline \multirow[t]{2}{*}{ Attributes } & \multicolumn{5}{|c|}{ Tool } \\
\hline & AHP & Delphi & Brainstorming & $\begin{array}{l}\text { Nominal Group } \\
\text { Technique }\end{array}$ & AHP-Delphi \\
\hline $\begin{array}{l}\text { Transparency } \\
\text { and reliability }\end{array}$ & $\begin{array}{l}\text { Systematic and } \\
\text { consistent. It is able to } \\
\text { assemble the decision- } \\
\text { making process orderly } \\
\text { and foster transparent } \\
\text { judgments }\end{array}$ & $\begin{array}{l}\text { It may generate } \\
\text { controversy, according } \\
\text { to Goodman (1987), due } \\
\text { to anonymity. The lack } \\
\text { of accuracy can create a } \\
\text { mistrust of the } \\
\text { stakeholders }\end{array}$ & $\begin{array}{l}\text { It is transparent, } \\
\text { however, due to } \\
\text { difficulty of objectivity } \\
\text { may generate criticisms } \\
\text { regarding its reliability }\end{array}$ & $\begin{array}{l}\text { It is transparent, } \\
\text { however, due to } \\
\text { difficulty of objectivity } \\
\text { may generate criticisms } \\
\text { regarding its reliability }\end{array}$ & $\begin{array}{l}\text { Systematic and } \\
\text { consistent. It is able to } \\
\text { assemble the decision- } \\
\text { making process orderly } \\
\text { and foster transparent } \\
\text { judgments. Delphi } \\
\text { technique reduces the } \\
\text { AHP inconsistencies }\end{array}$ \\
\hline $\begin{array}{l}\text { Low level of } \\
\text { subjectivity }\end{array}$ & $\begin{array}{l}\text { It turns quantitative } \\
\text { data into qualitative. It } \\
\text { reduces the problem of } \\
\text { subjectivity }\end{array}$ & $\begin{array}{l}\text { quantitative and } \\
\text { qualitative data. It is } \\
\text { able to reduce } \\
\text { subjectivity }\end{array}$ & $\begin{array}{l}\text { High level of } \\
\text { subjectivity }\end{array}$ & $\begin{array}{l}\text { High level of } \\
\text { subjectivity }\end{array}$ & $\begin{array}{l}\text { It turns quantitative } \\
\text { data into qualitative. It } \\
\text { reduces the problem of } \\
\text { subjectivity }\end{array}$ \\
\hline $\begin{array}{l}\text { Supporting for } \\
\text { decision making } \\
\text { prone to } \\
\text { updating }\end{array}$ & $\begin{array}{l}\text { If there is no change in } \\
\text { the weights of criteria, it } \\
\text { is possible to re-apply } \\
\text { the technique to obtain } \\
\text { another option }\end{array}$ & $\begin{array}{l}\text { It would be required } \\
\text { another round of the } \\
\text { Delphi method - } \\
\text { considering the updates } \\
\text { coming from the interest } \\
\text { group }\end{array}$ & $\begin{array}{l}\text { It would be required a } \\
\text { new brainstorming } \\
\text { session for information } \\
\text { updates }\end{array}$ & $\begin{array}{l}\text { It would be required a } \\
\text { new NGT session for } \\
\text { information updates }\end{array}$ & $\begin{array}{l}\text { If there is no change in } \\
\text { the weights of criteria, it } \\
\text { is possible to re-apply } \\
\text { the technique to obtain } \\
\text { another option }\end{array}$ \\
\hline $\begin{array}{l}\text { Multicriteria } \\
\text { analysis }\end{array}$ & $\begin{array}{l}\text { It is one of the most } \\
\text { known and efficient } \\
\text { MCDA methods }\end{array}$ & $\begin{array}{l}\text { It can be used for } \\
\text { multicriteria decision } \\
\text { making, whether } \\
\text { quantitative or } \\
\text { qualitative }\end{array}$ & $\begin{array}{l}\text { Although it can handle } \\
\text { with multicriteria } \\
\text { problems at the same } \\
\text { time, may be } \\
\text { complications due to its } \\
\text { subjectivity }\end{array}$ & $\begin{array}{l}\text { Although it can handle } \\
\text { with multicriteria } \\
\text { problems at the same } \\
\text { time, may be } \\
\text { complications due to its } \\
\text { subjectivity }\end{array}$ & $\begin{array}{l}\text { Its multicriteria analysis } \\
\text { is based on AHP } \\
\text { technique }\end{array}$ \\
\hline
\end{tabular}

Ease of deployment

\section{$-1,10,10$}

It is considered the opinion of one expert per time. Easy data gathering, and results achievement

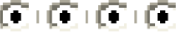

It is considered the opinion of one expert per time. Easy data gathering, but may occur some difficulty in data obtaining if the problem complexity requires a high number of sessions subjectivity

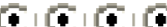

Ease of deployment.

However, the main

difficulty is to gather all participants (experts) at the same time subjectivity

\section{$\%$}

Ease of deployment.

However, the main

difficulty is to gather all participants (experts) at the same time

\section{$10^{\circ}, \sigma^{\circ}, \sigma^{\circ}$}

It is considered the opinion of one expert per time. Easy data gathering, and results achievement 
of factors such as academic or professional status, also their oratorical ability will not influence the reliability/validity of their arguments. Thus, the anonymity in Delphi method is an important topic to be considered. Brainstorming can obscure the view of some participants, and even that it has an organized brainstorming - NGT - it would present some influence because of the presence of other participants.

One of the important characteristics of the AHP is the ability to structure the problem into hierarchical levels. This tool scores each attribute relevance of multicriteria problem, and thus it is possible to separate each criterion into importance levels. Ending this ranking and the matrix construction (for criteria judgment), it also presents a coherence level to measure the quality of judgments made by the experts.

A well-defined criterion of when to stop, in several other decision support tools (Delphi, for example), is not clear. A Delphi round is closed when it reaches an apparent consensus among the participants. But, this way, Delphi creates the possibility of some inconsistency that has not been noticed by experts during the judgment process.

Although it has subjectivity in some attributes, according to Costa [18], one of the main advantages of MCDM method is that on it, it is possible to recognize the inherent subjectivity of decision-making problems, thus using value judgment as a way to treat it scientifically. On the problem of deep geological repository siting, subjective criteria are present along the entire process, so it is essential that the selected tool also covers this type of situation.

Due to the importance and some controversies related to nuclear power, the choice for final deep geological repository should be reliable and transparent, so community and public agencies will be convinced about its real safety and costs. In Delphi method, according to Wright and Giovinazzo [30], some disadvantages related to method transparency and credibility were pointed out, such as forcing consensus unduly, difficult to draft a questionnaire unambiguous and not biased, and excessive dependence of the results regarding the experts' choice. Therefore, AHP is a good option, since it presents a transparent and reliable method that encompasses both qualitative and quantitative factors in a structured and consistent process.

A combined decision support tool AHP-Delphi method provides an option that embraces the different qualities of these two processes, thereby optimizing the decision making. Both tools work in an integrated manner: Delphi method increases the AHP technique power, but also keeping its advantages. While the AHP allows participants to know each attribute priorities, its relative weights - in pairwise comparisons - and the level of consistency of their decisions, then, Delphi allows an information return (to decisions) of other members.

AHP-Delphi keeps the AHP qualities, and due to this information return characteristic of Delphi, it allows a cutback of inconsistencies usually generated by AHP, and in many cases, it may improve the outcomes; since this tool assumes that decision makers and experts are inconsistent in their value judgments regarding decision criteria and alternatives [14]. The information return, in this case, also works as an improvement for understanding the problem, 
considering that no experts know all the areas addressed by the problem in its entirety. In this sense, it is possible to gather opinions more informed/consistent, due to these constant updates of information during an AHP-Delphi method session.

Summing up, the AHP-Delphi method was best suited for decision making in selecting an appropriate location for constructing a final deep geologic repository for high level nuclear waste.

The authors would like to thank the Program of Nuclear Energy (COPPE/UFRJ), Celso Suckow Fonseca Federal Center for Technological Education for their support.

\section{Nomenclature}

IAEA International Atomic Energy Agency

CHG Greenhouse Gases

MCDM Multiple-Criteria Decision Making

AHP Analytic Hierarchy Process

NGT The Nominal Group Technique

\section{References}

1. F.M. Vichi, L.F. Mello, in Energy: its use and the environment, 3rd edn. (Thomson Learning, São Paulo, 2003), Chap. 19

2. L. Indriunas, HowStuffWorks: How it works controversy over the nuclear plants, 2008, http://ambiente.hsw.uol.com.br/ polemica-sobreusinas-nucleares.htm

3. G. Bertozzi et al., Safety assessment of radioactive disposal into geological formation (Commission of the European Community, Luxembourg, 1978)

4. A. Pritzker, J. Gassmann, Application of simplified reliability methods for risk assessment of nuclear waste repository, Nucl. Technol. 48, 289 (1980)

5. S.H. Chang, W.J. Cho, Risk analysis of radioactive waste repository based on the time dependent hazard rate, Radioactive Waste Manage. Nucl. Fuel Cycle 5, 63 (1984)

6. B.L. Cohen, A generic probabilistic risk assessment for low level waste burial grounds, Nucl. Chem. Waste Manage. 5, 39 (1984)

7. C.M. Malbrain, Risk assessment and the regulation of high level waste repository, D.Sc. dissertation, Massachusetts Institute of Technology, Cambridge, 1984

8. P.O. Kim, W.J. Cho, S.H. Chang, Probabilistic safety assessment of low level wasted disposal system, Radioactive Waste Manage. Nucl. Fuel Cycle 10, 253 (1988)

9. K.W.J. Han, C.H. Kang, C.H. Kim, Genetic safety assessment for LLW repository, in Anais do Joint International Waste Management Conference, 1991 (1991)

10. T.W. Krishnamoorthy et al., Models for shallow land disposal of low and intermediate level radwastes, in Anais do Joint International Waste Management Conference, 1991 (1991), Vol. 1, p. 127

11. J.B. Garrick, The use of risk assessment to evaluate waste disposal facilities in the United States of America, Saf. Sci. 40, $135(2002)$

12. R.H. Little, J.S.S. Penfold, Preliminary safety assessment of concepts for a permanent waste repository at the Western Waste Management Facility, Summary Report, March 2003
13. D. Ene, Test case of the long-term preliminary performance assessment for the LEIL Radioactive Waste Repository Baita Bihor (ICRS, Madeira, Romania, 2004)

14. V.B. Martins, A geographic information system and multicriteria analysis method for site selection of spent nuclear fuel disposal, PhD Thesis, COPPE/UFRJ, Rio de Janeiro, RJ, Brasil, 2009

15. IAEA, Arms control \& verification: safeguards in a changing world (International Atomic Energy Agency, Vienna, 1997), Vol. 39, n. 5, pp. 4-11

16. IAEA, Radioactive waste management glossary (International Atomic Energy Agency, Vienna, 2003)

17. IAEA, Qualitative acceptance criteria for radioactive wastes to be disposed of in deep geological formations (International Atomic Energy Agency, Vienna, 1990)

18. H.G. Costa, Support to Multicriteria Decision: AHP method (ABEPRO, Rio de Janeiro, 2006)

19. F.A.E. Lozano, Selecting sites for tailings dams using hierarchical analysis method, Master's thesis, Polytechnic/ USP, São Paulo, SP, Brasil, 2006

20. T.L. Saaty, The analytic hierarchy process (McGraw-Hill, New York, 1980)

21. J.R. Emshoff, T.L. Saaty, Applications of the analytic hierarchy process to long range planning processes, Eur. J. Oper. Res. 10, 131 (1982)

22. R. Armacost, J. Hosseini, Identification of determinant attributes using the analytic hierarchy process, J. Acad. Mark. Sci. 22, 383 (1994)

23. N. Bryson, Group decision-making and the analytic hierarchy process: exploring the consensus-relevant information content, Comput. Oper. Res. 23, 27 (1996)

24. S.R. Granemann, I.R. Gartner, Selection of financing for acquisition of aircraft: an application of the Analytic Hierarchy Process (AHP), Mag. Transp. 6, 18 (1998)

25. A. Figueiredo, I.R. Gartner, Planning for management actions for quality and productivity in urban transport, in Transportation in transformation II (Makron, São Paulo, 1999)

26. I.R. Gartner, N. Casarotto Filho, B.H. Kopittke, A multicriteria system to support the project analysis developing banks, Mag. Prod. Prod. CEREPBR 2, 75 (1998)

27. A.T. Cruz Jr, M.M. Carvalho, Consumer voice obtaining: study of case on a Green Hotel, Production 13, 88 (2003)

28. E. Bischoff, Studies using genetic algorithms for selecting access networks, Master's thesis in Electrical Engineering, Department of Electrical engineering, University of Brasília, Brasília, DF, 2008, p. 142

29. N.C. Dalkey, B. Brown, S. Cochran, The Delphi Method. III: Use of self rating to improve group estimates (The Rand Corporation, Santa Monica, 1969), http://www.rand.org/ content/dam/rand/pubs/research_memoranda/2006/ RM6115.pdf

30. J.T.C. Wright, R.A. Giovinazzo, Delphi: a support tool to prospective planning, Notebooks Res. Management 1, 54 (2000)

31. D.M. Georgoff, R.G. Murdick, Manager's guide to forecasting, Harv. Bus. Rev. 64, 110 (1986)

32. J. Preble, Public sector use of the Delphi technique, Technol. Forecast. Soc. Change 23, 75 (1983)

33. U. Gupta, R. Clarke, Theory and application of Delphi technique: A Bibliography (1975-1994), Technol. Forecast. Soc. Change 53, 185 (1996) 
34. S.C. Wheelwright, S. Makridakis, Forecasting methods for management, 4th edn. (John Wiley, New York, 1985)

35. H. Sackman, Delphi critique: expert opinion, forecasting, and group process (Lexington Book, Lexington, Massachusets, 1975)

36. M.A. Linstone, M. Turoff, The Delphi method techniques and application (Wesley Publishing Company Inc, Addison, New York, 1975)

37. A. Bacelo, K. Becker, A Support Tool and Discussion Deliberation Group, in Proceedings of the Third Workshop on Multimedia Systems and Hypermedia, São Carlos, 1997 (1997), pp. 119-130

38. A. Chauvet, Management methods: the Guide (Instituto Piaget, Lisbon, 1995)

39. A. Goicoechea, D.R. Hansen, L. Duckstein, The Nominal Group Technique, in Multiobjective decision analysis with engineering and business applications (John Wiley \& Sons, New York, 1982), pp. 361-363

40. B. Al-Kloub, T. Al-Shemmeri, A. Pearman, The role of weights in multi-criteria decision aid, and the ranking of water projects in Jordan, Eur. J. Oper. Res. 99, 278 (1997)

41. S.H.B. Cassiani, L.P. Rodrigues, The Delphi technique and The Nominal Technical Group as collection strategies data from nursing research, Acta Paul. Enf. 9, 81 (1996)

42. L.M. Jessup, D.A. Tansik, Decision making in an automated environment: the effect of anonymity and proximity with a Group Decision Support System, Decis. Sci. 2, 266 (1991)
43. J.W. Wilkinson, Accounting and information systems (John Wiley \& Sons, New York, 1991)

44. R.S. Kaplan, A.A. Atkinson, in Advanced management accounting (Prentice Hall, Englewood Cliffs, 1989), pp. $473-496$

45. R.S. Kaplan, A.A. Atkinson, in Advanced management accounting (Prentice Hall, Englewood Cliffs, 1989), pp. 719-740

46. IAEA, Selection factors for repositories of solid high-level and alpha-bearing wastes, International Atomic Energy Agency, Geological Formations, Technical Report Series, No. 177, Vienna, 1977

47. IAEA, Concepts and examples of safety analyses for radioactive waste repositories, International Atomic Energy Agency, Continental Geological Formations, Safety Series, No. 58, Vienna, 1983

48. IAEA, Safety principles and technical criteria for the underground disposal of high level radioactive wastes, International Atomic Energy Agency, Safety Series, No. 99, Vienna, 1989

49. K.P. Yoon, C.L. Hwang, Multi attribute decision making: an introduction (Thousand Oaks, CA, 1995)

50. J. Malczewski, GIS and multicriteria decision analysis (John Wiley \& Sons, New York, 1999)

51. R.L. Keeney, H. Raiffa, R.F. Meyer, Decisions with multiple objectives: preferences and value tradeoffs (Cambridge University Press, Cambridge, UK, 1993)

Cite this article as: Jonni Guiller Madeira, Antônio Carlos M. Alvim, Vivian B. Martins, Nilton A. Monteiro, Selection of a tool to decision making for site selection for high level waste, EPJ Nuclear Sci. Technol. 2, 6 (2016) 